\title{
Evaluation of lactic acid bacteria strains isolated from fructose-rich environments for their mannitol-production and milk-gelation abilities
}

\author{
Pradip V. Behare, ${ }^{1} \odot$ Shahneela Mazhar, ${ }^{2} \odot$ Vincenzo Pennone, ${ }^{2}$ (๑) and Olivia McAuliffe ${ }^{2,3 *}$ (1) \\ ${ }^{1}$ Dairy Microbiology Division, Indian Council of Agricultural Research (ICAR)-National Dairy Research Institute, Karnal-132001, Haryana, India \\ ${ }^{2}$ Teagasc Food Research Centre, Moorepark, Fermoy, Co. Cork, P61 C996 Ireland \\ ${ }^{3}$ VistaMilk SFI Research Centre, Moorepark, Fermoy, Co. Cork, P61 C996 Ireland
}

\section{ABSTRACT}

Mannitol is a sugar alcohol, or polyol, widely used in the food industry because of its low-calorie properties. Industrial production of mannitol is difficult and expensive. However, certain bacterial species are known to produce mannitol naturally, including certain lactic acid bacteria and fructophilic lactic acid bacteria (LAB). In this study, bacterial strains isolated from fructose-rich sources, including flowers, leaves, and honey, were identified by $16 \mathrm{~S}$ rRNA sequence analysis as Leuconostoc, Fructobacillus, Lactococcus, and Lactobacillus species and 4 non-LAB species. DNA profiles generated by pulsed-field gel electrophoresis discriminated 32 strains of Leuconostoc mesenteroides and 6 Fructobacillus strains. Out of 41 LAB strains isolated, 32 were shown to harbor the $m d h$ gene, which encodes the mannitol dehydrogenase enzyme, and several showed remarkable fructose tolerance even at $50 \%$ fructose concentrations, indicating their fructophilic nature. Several of the strains isolated, including Leuconostoc mesenteroides strains DPC 7232 and DPC 7261, Fructobacillus fructosus DPC 7237, and Fructobacillus fructosus DPC 7238, produced higher mannitol concentrations than did the positive control strain Limosilactobacillus reuteri DSM 20016 during an enzymatic screening assay. Mannitol concentrations were also examined via HPLC in 1\% fructose de Man, Rogosa, and Sharpe medium (FMRS) or 1\% fructose milk (FM). Among the strains, Fructobacillus fructosus DPC 7238 displayed high fructose utilization $(9.27 \mathrm{~g} / \mathrm{L})$, high mannitol yield $(0.99 \mathrm{~g}$ of mannitol/g of fructose), and greatest volumetric productivities $(0.46 \mathrm{~g} / \mathrm{L}$ per $\mathrm{h})$ in FMRS. However, Leuconostoc mesenteroides DPC 7261 demonstrated the highest fructose utilization $(8.99 \mathrm{~g} / \mathrm{L})$, mannitol yield (0.72 $\mathrm{g}$ of mannitol/g of fructose), and

Received June 19, 2020.

Accepted July 20, 2020.

*Corresponding author: olivia.mcauliffe@teagasc.ie volumetric productivities $(0.04 \mathrm{~g} / \mathrm{L}$ per h) in FM. Storage modulus $\mathrm{G}^{\prime}(>0.1 \mathrm{~Pa})$ indicated a shorter gelation time for Limosilactobacillus reuteri DSM 20016 (8.73 h), followed by F. fructosus DPC $7238(11.57 \mathrm{~h})$ and $L$. mesenteroides DPC 7261 (14.52 h). Our results show that fructose-rich niches can be considered important sources of fructophilic LAB strains, with the potential to be used as starter cultures or adjunct cultures for the manufacture of mannitol-enriched fermented dairy products and beverages.

Key words: FLAB, Leuconostoc, Fructobacillus, mannitol, milk gelation

\section{INTRODUCTION}

Lactic acid bacteria (LAB) are ubiquitously present in a variety of environments, including fermented dairy products, meat products, cereals, plants, flowers, fruits, and vegetables (Mozzi et al., 2006; Dhakal et al., 2012; Ruiz Rodríguez et al., 2019). Often, LAB from diverse sources display diverse metabolic properties as a result of environmental adaptation (Tyler et al., 2016). In particular, fructose-rich niches are potential reservoirs for candidate LAB species with undiscovered functional traits (Di Cagno et al., 2013; Endo and Salminen, 2013). Species such as Weissella confusa, Weissella cibaria, Levilactobacillus brevis, Lactiplantibacillus plantarum, Leuconostoc mesenteroides, Leuconostoc pseudomesenteroides, Lactococcus lactis, Enterococcus faecalis, and Enterococcus durans are the most frequent species isolated from these sources (Askari et al., 2012; Ong et al., 2012; Leong et al., 2014). In the recent past, fructophilic lactic acid bacteria (FLAB) have been reported in fructose-rich fruits, flowers, and vegetables (Di Cagno et al., 2013; Endo and Salminen, 2013; Olofsson et al., 2014). Their fructophilic nature, or their ability to tolerate high concentrations of fructose, was thought to be unique to the Fructobacillus genus, a genus which arose from a reclassification of the Leuconostoc species. However, this property is also observed in some Lactobacillus species (Endo et al., 2018; Filannino et al., 
2019; Ruiz Rodríguez et al., 2019), suggesting that other genera and species are also fructophilic in nature. To date, Fructobacillus fructosus, Fructobacillus durionis, Fructobacillus ficulneus, Fructobacillus tropaeoli, Apilactobacillus kunkeei, Apilactobacillus apinorum, Fructilactobacillus florum, and Lactiplantibacillus plantarum have been reported as FLAB species from fructose-rich sources, including fructose-consuming insects (Endo et al., 2010; Ruiz Rodríguez et al., 2017; Gustaw et al., 2018). Recently, FLAB have received some interest due to certain properties, including the production of polyols and acting as probiotic cultures for honeybees (McFrederick et al., 2012; Vásquez et al., 2012; Endo et al., 2018).

The FLAB differ from other LAB species because they prefer fructose over glucose as a growth substrate (Endo et al., 2009). Growth of FLAB on glucose is poor but can be enhanced in the presence of external electron acceptors such as pyruvate, oxygen, or fructose (Endo and Okada, 2008). Many heterofermentative LAB and FLAB (Limosilactobacillus fermentum, Lactobacillus intermedius, Limosilactobacillus reuteri, F. tropaeoli, and $F$. fructosus) synthesize mannitol when an alternative electron acceptor such as fructose is present in the medium (Ortiz et al., 2017). Mannitol is a sugar alcohol, or polyol, widely used in the food, pharmaceutical, and chemical industries. Because of its low calorie content, mannitol is increasingly attracting interest as a sugar substitute, or sweetener, for diabetics and others with sugar intolerance. One-step conversion of fructose to mannitol is catalyzed by the enzyme mannitol dehydrogenase (MDH; EC 1.1.1.67), requiring either NADH or NADPH as cofactors (Bhatt et al., 2012). Expression of the $m d h$ gene is markedly induced by the presence of fructose in the early stages of microbial growth (Ortiz et al., 2017).

To date, FLAB remain unevaluated in dairy applications. Therefore, in this study, we aimed to isolate and characterize $\mathrm{LAB}$, including FLAB, from fructose-rich niches and to evaluate these strains in terms of their in situ mannitol production and gelation behavior in milk.

\section{MATERIALS AND METHODS}

\section{Sample Collection for Isolation of LAB/FLAB}

In total, 19 samples from fructose-rich sources were collected from 3 different locations in Ireland. Eleven samples, comprising fresh-cut flowers, leaves, and honey, were obtained from a farm in County Tipperary. Four flower samples were obtained from a garden center in Kilworth, County Cork. Fruit (grapes and bananas) and vegetable (cauliflower and spinach) samples were purchased from a local market, in Fermoy, County Cork. All samples were collected aseptically and stored at $4^{\circ} \mathrm{C}$ until further analysis.

\section{Isolation of FLAB Using Fructose-Containing Media}

Five grams of each sample was added to $10 \mathrm{~mL}$ of maximum recovery diluent (MRD; $8.5 \mathrm{~g} / \mathrm{L}$ of sodium chloride and $1.0 \mathrm{~g} / \mathrm{L}$ of peptone) and homogenized. Appropriate serial dilutions of each sample suspension were plated onto 2 different agars supplemented with 10 $\mathrm{g} / \mathrm{L}$ of fructose: fructose yeast peptone (FYP) agar, as described by Endo et al. (2009), and fructose de Man, Rogosa, and Sharpe agar (MRS; with fructose, this will be termed FMRS; Becton, Dickinson and Company, Wokingham, UK). The FYP and FMRS agar plates were incubated aerobically at $30^{\circ} \mathrm{C}$ for 24 to $48 \mathrm{~h}$. Small to medium-sized colonies were selected and inoculated into each of FYP and FMRS broth containing $10 \mathrm{~g} / \mathrm{L}$ of fructose, followed by incubation aerobically at $30^{\circ} \mathrm{C}$ for $24 \mathrm{~h}$. Mixed cultures were purified by streak plate using FYP or FMRS agar. Limosilactobacillus reuteri DSM 20016 and Lactococcus lactis DPC 6665 were used as MDH-positive and -negative cultures, respectively, for the various assays performed in the study. These strains were cultured in FMRS at $37^{\circ} \mathrm{C}$ for DSM 20016 and M17 (Oxoid, Basingstoke, UK), supplemented with $0.5 \%$ (wt/vol) lactose at $30^{\circ} \mathrm{C}$ for DPC 6665 .

\section{Genotypic Characterization}

Genomic DNA was extracted from the isolates using the Ultra Clean Microbial DNA Isolation Kit (Mo-Bio Laboratories, Cambridge, UK) after overnight growth of cultures at $30^{\circ} \mathrm{C}$ in FMRS. Species identification was determined using the method described by Alander et al. (1999). The $16 \mathrm{~S}$ rRNA amplicons $(\approx 1,500 \mathrm{bp})$ were then purified by ISOLATE II PCR and Gel Kit (BIO-52060; Bioline, Dublin, Ireland), according to the manufacturer's instructions. The concentration and purity of the isolated amplicons were measured using the Nanodrop-Spectrophotometer (NanoDrop 1000 Spectrophotometer; Thermo Scientific, Dublin, Ireland). Nucleotide sequences of purified PCR products were determined by Eurofins Genomics (European Custom Sequencing Centre, Germany). Sequence similarity analysis was conducted using the Basic Local Alignment Search Tool (BLASTn) program (http://www.ncbi .nlm.nih.gov/BLAST). The 16S rRNA gene sequences were compared with those available at the National Collection for Biotechnological Information GenBank database (accession nos. NR_113960.1, NR_104925.1, NR_074957.1, $\quad$ NR_113579.1, $\quad$ MK986693.1, 
NR_042285.1, $\quad$ NR_104573.1, $\quad$ NR_113901.1, NR_115605.1, $\quad$ NR_025341.1, $\quad$ NR_118557.1, NR_157602.1, and NR_113957.1). For species assignation, isolates that showed maximum similarity percentage $(\geq 87.50 \%)$ with the reference strain in the database were considered.

\section{Pulsed-Field Gel Electrophoresis (PFGE) Analysis}

The FLAB isolates were grown in FMRS broth at $30^{\circ} \mathrm{C}$ overnight. The cell pellet was obtained by centrifugation of $1.5 \mathrm{~mL}$ of culture at $5,000 \times g$ for $10 \mathrm{~min}$ and washed twice with buffer $(1 M \mathrm{NaCl}, 10 \mathrm{~m} M$ Tris$\mathrm{HCl}, \mathrm{pH}$ 7.6). The pellet was suspended in $200 \mu \mathrm{L}$ of the same buffer and vortexed for $5 \mathrm{~s}$. To the cell suspension, an equal volume of $2 \%$ (wt/vol) low melting point agarose (Sigma-Aldrich Co., St. Louis, MO) in $0.125 \mathrm{M}$ EDTA, pH 7.0, was added and dispensed into a plug mold. DNA plugs were prepared as per the method described by Pogačić et al. (2014) and according to the PulseNet protocol (Hunter et al., 2005). The strain Salmonella enterica ssp. enterica serovar Braenderup (ATCC BAA664) was used as reference strain. All the plugs were stored in TE buffer $(10 \mathrm{~m} M$ Tris-HCl, $1 \mathrm{~m} M$ EDTA, $\mathrm{pH} 8.0)$ at $4^{\circ} \mathrm{C}$ until digestion.

For DNA digestion, plugs were equilibrated for at least 30 min in $1 \times$ CutSmart Buffer (New England Biolabs Inc., Ipswich, MA) at $4^{\circ} \mathrm{C}$ and transferred to fresh digestion buffer containing $20 \mathrm{U}$ of restriction enzyme (SmaI or SfiI for DNA from FLAB isolates, and $X b a \mathrm{I}$ for DNA from reference strain). Plugs with restriction enzyme added were incubated at the optimum temperature for activity of each enzyme $\left(S m a \mathrm{I}, 25^{\circ} \mathrm{C}\right.$ for $5 \mathrm{~h}$; $S f i \mathrm{I}, 50^{\circ} \mathrm{C}$ for $5 \mathrm{~h}$; and $\mathrm{XbaI}, 37^{\circ} \mathrm{C}$ for $3 \mathrm{~h}$ ). After digestion, the plugs were cut into slices, placed on the tip of the gel comb, and loaded into the wells of a 1\% (wt/ vol) pulsed-field gel electrophoresis (PFGE) agarose gel (Bio-Rad Laboratories Inc., Hercules, CA) prepared in $0.5 \times$ TRIS borate EDTA buffer (Sigma-Aldrich). The PFGE was run at $6 \mathrm{~V} / \mathrm{cm}$ for $22 \mathrm{~h}$ at $14^{\circ} \mathrm{C}$ with the pulse ramped from 1 to $20 \mathrm{~s}$ on a CHEF-DR III unit (Bio-Rad). Gels were stained for $2 \mathrm{~h}$ with ethidium bromide $(0.5 \mu \mathrm{g} / \mathrm{mL})$ made in distilled water, followed by destaining in distilled water for $30 \mathrm{~min}$, and visualized using the Alpha Imaging System (Alpha Innotech, BioSurplus, San Diego, CA). Images were imported to Bionumerics version 7.6 (Applied Maths, Sint-MartensLatem, Belgium), and PFGE profiles were compared.

\section{PCR to Detect mdh Gene}

Primers were designed using the $m d h$ gene sequence of Leuconostoc pseudomesenteroides KCTC 3652 (accession number AJ486977) as a reference with Primer3 software (http://bioinfo.ut.ee/primer3-0.4.0/ ), using set parameters, with predicted product size range between 150 and $200 \mathrm{bp}$. The primer sequences F-5'CTGCAAGCTTATGGCATTCA-3' and R-5' AATTGCGGCTTCTTGTGTCT-3 were synthesized by Sigma-Aldrich (Wicklow, Ireland). Genomic DNA samples were used as template DNA for $m d h$ PCR. Gradient PCR was run with $m d h$-positive Limosilactobacillus reuteri DSM 20016, using temperature gradient of 55 to $65^{\circ} \mathrm{C}$, by Prime Thermocycler (Techne Prime, Staffordshire, UK). The mdh PCR protocol consisted of the initial denaturation steps of $94^{\circ} \mathrm{C}$ for 5 min, followed by 35 cycles of $45 \mathrm{~s}$ at $94^{\circ} \mathrm{C}, 35 \mathrm{~s}$ annealing at $58^{\circ} \mathrm{C}, 30 \mathrm{~s}$ extension at $72^{\circ} \mathrm{C}$, and a final extension at $72^{\circ} \mathrm{C}$ for $10 \mathrm{~min}$.

\section{Evaluation of Fructose Tolerance}

Fructose tolerance of the $m d h$-positive LAB strains was determined as per the method of Gustaw et al. (2018), with some modifications. The LAB cultures were inoculated at $3 \%(\mathrm{vol} / \mathrm{vol})$ into each of $10 \mathrm{~mL}$ FMRS broth comprising 0, 10, 20, 30, 40, and 50\% (wt/ vol) D-fructose, followed by incubation at $30^{\circ} \mathrm{C}$ for $20 \mathrm{~h}$. Following incubation, the cultures were serially diluted in MRD and plated onto FMRS agar and incubated at $30^{\circ} \mathrm{C}$ for $48 \mathrm{~h}$. Visible colonies on FMRS agar were counted after $48 \mathrm{~h}$ and denoted as initial viable count (N0) for growth in broth in the absence of fructose and final viable count (N1) for growth in broth containing fructose. Percentage of fructose tolerance was calculated using the following formula:

$$
\begin{gathered}
\text { Fructose tolerance }(\%)= \\
\text { Log cfuN1/Log cfuN0 } \times 100 .
\end{gathered}
$$

\section{Screening of FLAB for Mannitol Production}

$M d h$-positive FLAB strains were screened for mannitol production via enzyme assay. Based on the preliminary trials, cultures were inoculated at $3 \%$ (vol/vol) into $10 \mathrm{~mL}$ of FMRS broth and incubated in a shaking incubator (Sartorius Stedim Certomat BS-1, Labequip Ltd., Ontario, Canada) at $30^{\circ} \mathrm{C}$ for $20 \mathrm{~h}$ with constant speed of $100 \mathrm{rpm}$. The fermented FMRS broth was centrifuged at $10,000 \times g$ for $10 \mathrm{~min}$ at room temperature, and the supernatant was collected. Mannitol production was determined using a D-Mannitol/L-Arabitol Assay Kit (Megazyme, Wicklow, Ireland). A calibration curve, using mannitol standards, was prepared in a standard 96-well flat-bottomed microplate (Sarstedt, Wexford, Ireland). For sample analysis, solution 1 (buf- 
fer) and solution $2\left(\mathrm{NAD}^{+}\right)$from the Megazyme kit, along with distilled water, were added to the sample supernatants. The microplate was loaded onto a Synergy HT microplate reader (Biotek, Mason Technology Ltd., Dublin, Ireland), allowing shaking option for $10 \mathrm{~s}$, and absorbance readings $\left(\mathrm{A}_{1}\right)$ were noted after $2 \mathrm{~min}$ at 340 $\mathrm{nm}$. Then, suspension 3 from the Megazyme kit, comprising mannitol dehydrogenase (MDH), was added to the sample mixtures. The microplate was again loaded onto the reader with shaking for $10 \mathrm{~s}$, and absorbance readings $\left(\mathrm{A}_{2}\right)$ were taken at $340 \mathrm{~nm}$ after $4 \mathrm{~min}$. The absorbance difference $\left(A_{2}-A_{1}\right)$ was determined for a water blank $\left(\mathrm{A}_{1}\right)$ and sample $\left(\mathrm{A}_{2}\right) . \Delta \mathrm{A}_{\mathrm{D}-\text { mannitol was }}$ obtained by subtracting absorbance difference of the blank from the absorbance difference of the sample. Mannitol concentration $(\mathrm{g} / \mathrm{L})$ was determined from the calibration curve equation $(\mathrm{y}=0.042 \mathrm{x}+0.150)$, where $\mathrm{y}=\Delta \mathrm{A}_{\mathrm{D} \text {-mannitol }}$ and $\mathrm{x}=$ concentration of mannitol in the samples.

\section{Determination of Mannitol Content by HPLC}

Batch fermentation was performed with selected mannitol-producing FLAB strains in each of $200 \mathrm{~mL}$ FMRS broth and 1\% fructose milk (FM). Fermented milk was prepared by dissolving $12 \%$ skim milk powder (wt/vol) and $1 \%$ fructose (wt/vol) in distilled water at $45^{\circ} \mathrm{C}$, followed by sterilization at $115^{\circ} \mathrm{C}$ for $5 \mathrm{~min}$. The fermentation parameters were set as follows: culture inoculums of $3 \%$, (vol/vol) were used, with temperature $\left(30^{\circ} \mathrm{C}\right)$, agitation $(100 \mathrm{rpm})$, and shaking time $(20$ h) set as described. Centrifugation followed, to obtain supernatant. In the case of FM, samples were first deproteinized by adding an equal volume of ice-cold 1 $M$ perchloric acid, and the supernatant was obtained by centrifugation at $1,500 \times g$ for $10 \mathrm{~min}$. The supernatants from FMRS and FM were passed through a $0.2-\mu \mathrm{m}$ nylon filter.

Fructose and mannitol content were analyzed by HPLC (Alliance 2695, Waters Corp., Milford, MA), using an Aminex HPX-87C column (Bio-Rad), following the protocol of Carvalheiro et al. (2011) with some modifications. The HPLC column was maintained at $60^{\circ} \mathrm{C}$, and the mobile phase used was $0.009 \mathrm{~N} \mathrm{H}_{2} \mathrm{SO}_{4}$ at flow rate of $0.5 \mathrm{~mL} / \mathrm{min}$. Single standard solutions of both fructose and mannitol were prepared at a concentration of $1 \mathrm{mg} / \mathrm{mL}$ to establish elution times. Quantification was based on the external standard method, and calibration curves for the 2 sugars using different concentrations $(10,20,50$, and $100 \mu \mathrm{g} / \mathrm{mL})$ were generated in a linear response. All the compounds were analyzed and quantified with a refractive index detector (Waters Corp.).

\section{Calculation of Parameters}

The fructose consumption rate, expressed in $\mathrm{g} / \mathrm{L}$, was obtained by subtracting the fructose content after fermentation from the fructose content before fermentation in the sample. Fructose consumption rate (qs, $\mathrm{g} / \mathrm{L}$ per $\mathrm{h}$ ) was calculated by dividing the fructose consumed by fermentation time (h). The yield of mannitol $\left(\mathrm{Y}_{\mathrm{Man}}\right)$ from fructose is expressed in grams per gram and calculated as follows: $\mathrm{Y}_{\text {Man }}=$ mannitol produced divided by fructose consumed in the sample. Volumetric mannitol production rate, $\mathrm{Q}_{\mathrm{Man}}(\mathrm{g} / \mathrm{L}$ per $\mathrm{h})$, was calculated as mannitol produced in the sample divided by the fermentation time (h). Specific mannitol production rate $\left(\mathrm{q}_{\mathrm{Man}}\right)$ was calculated by dividing $\mathrm{Q}_{\mathrm{Man}}$ by wet biomass $(\mathrm{g} / \mathrm{L})$.

\section{Evaluation of FLAB for Milk Gelation Ability}

Milk gelation by FLAB strains was evaluated as per the method of Famelart et al. (2004), with some modifications. The elastic $\left(\mathbf{G}^{\prime}\right)$ and viscous $\left(\mathbf{G}^{\prime \prime}\right)$ moduli were monitored at $30^{\circ} \mathrm{C}$ for $\mathrm{FLAB}$ and at $37^{\circ} \mathrm{C}$ for DSM 20016 as a function of time in an AR2000 rheometer (TA Instruments, Waters, St. Quentin en Yvelines, France), in oscillatory mode with coaxial cylinder geometry at a frequency of $1 \mathrm{~Hz}$ and a strain of 0.02 . Twenty milliliters of FM inoculated with $3 \%$ (vol/vol) of the FLAB strain of interest was placed in the cup. Measurements were recorded dynamically at 30-s intervals. The gel time was defined as the point at which $\mathrm{G}^{\prime}$ $>0.1 \mathrm{~Pa}$.

\section{Statistical Analysis}

Enzymatic mannitol production experiments were performed in triplicate, and the results are expressed as mean \pm standard error of the mean (SEM). The data were statistically analyzed using Prism, version 7 (GraphPad Software, San Diego, CA), by one-way ANOVA with Tukey's post hoc test. Differences were considered statistically significant at least at $P<0.01$. Fructose tolerance values (mean \pm SEM) were obtained from 3 independent trials. Milk gelation experiments were carried out in duplicate.

\section{RESULTS}

\section{Isolation and Identification of LAB from Fructose-Rich Sources}

A total of 141 individual colonies isolated from samples of flowers, fruits, vegetables, leaves, and honey 
were selected from FYP and FMRS agar (Table 1). Out of these, 45 colonies grew well once purified in both FYP and FMRS broth. Pure isolates that showed turbidity in fructose-containing broth and appeared microscopically as LAB were considered as putative FLAB. Approximately $60 \%$ of the isolates were obtained from 4 flower types (foxglove, dandelion, white clover, and cotoneaster), whereas $40 \%$ were from 9 other samples (Table 1). Euphorbia, Cerinthe, and all fruit and vegetable samples tested did not yield any isolates.

For taxonomic identification of the isolates, $16 \mathrm{~S}$ rRNA gene sequence analysis was performed. The obtained 16S rRNA sequences were aligned and compared with the $16 \mathrm{~S}$ rRNA database in the GenBank library. Of the 45 isolates recovered, 41 were identified as LAB and 4 as non-LAB species (Enterococcus, Staphylococcus, Serratia, and Ewingella). Based on the sequence similarities, 32 of the $41 \mathrm{LAB}$ were identified as strains of $L$. mesenteroides (including 2 strains of subspecies $L$. mesenteroides ssp. jonggajibkimchii), 5 as F. fructosus, 2 as Lactococcus lactis, and 1 each as Fructobacillus durionis and Lactiplantibacillus plantarum (Supplemental Table S1, https://doi.org/10.3168/jds.2020 -19120). The cultures were deposited in the Teagasc
DPC Culture Collection, strains DPC 7230 to DPC 7274 (Supplemental Table S1).

\section{PFGE Characterization of Strains from Fructose-Rich Sources}

Two restriction enzymes, $S m a \mathrm{I}$ and $S f i \mathrm{I}$, were used for the discrimination of $32 \mathrm{~L}$. mesenteroides and 6 Fructobacillus strains, respectively. Cluster analysis revealed a similarity range between 30 and $100 \%$ for Leuconostoc and 70 to $100 \%$ for Fructobacillus strains (Figure 1). The Leuconostoc strains showed high variability, with similarity $<90 \%$, whereas the Fructobacillus strains were less variable. According to the profiles generated by $S m a I, L$. mesenteroides isolates were grouped into 25 pulsotypes: 5 with similarity $\geq 90 \%$ and 20 singletons (Figure 1A). According to the profiles generated by SfiI, 2 pulsotypes of Fructobacillus strains were identified. Fructobacillus fructosus DPC 7267, DPC 7235, and DPC 7239, DPC 7266, and F. fructosus DPC 7238 showed $>90 \%$ identity, whereas $F$. fructosus DPC 7237 showed $70 \%$ identity with the other genetic profiles (Figure 1B).

Table 1. Description of samples, numbers, and distribution of putative lactic acid bacteria (LAB) isolates

\begin{tabular}{|c|c|c|c|c|c|}
\hline \multirow[b]{2}{*}{ Name and type of sample } & \multirow[b]{2}{*}{ Botanical name } & \multirow[b]{2}{*}{ Designation $^{1}$} & \multirow[b]{2}{*}{$\begin{array}{l}\text { Selected } \\
\text { colonies }^{2}\end{array}$} & \multicolumn{2}{|c|}{ Putative LAB isolates } \\
\hline & & & & No. ${ }^{3}$ & $\%$ Distribution \\
\hline \multicolumn{6}{|l|}{ Farm, Co. Tipperary, Ireland } \\
\hline Herb robert, flower & Geranium robertianum & $\mathrm{HRG}$ & 11 & 3 & 7 \\
\hline White clover, flower & Trifolium repens & WCG & 15 & 5 & 11 \\
\hline Blackberry blossoms, flower & Rubus fruticosus & BBG & 13 & 4 & 9 \\
\hline Limnanthes douglasii, flower & Limnanthes douglasii & LDG & 7 & 2 & 5 \\
\hline Cotoneaster, flower & Cotoneaster horizontalis & $\mathrm{CG}$ & 14 & 6 & 13 \\
\hline Abutilon, flower & Abutilon pitcairnense & AG1 & 4 & 1 & 2 \\
\hline Foxglove, flower & Digitalis purpurea & FGG & 10 & 8 & 18 \\
\hline Dandelion, flower & Taraxacum officinale & DG & 12 & 8 & 18 \\
\hline Laurel leaves & Laurus nobilis, Lauraceae & LLG & 7 & 1 & 2 \\
\hline Dandelion leaves & Taraxacum officinale & DLG & 8 & 2 & 5 \\
\hline Raw honey & - & RHG & 5 & 1 & 2 \\
\hline \multicolumn{6}{|c|}{ Garden center, Kilworth, Co. Cork, Ireland } \\
\hline Euphorbia, flower & Euphorbia milii & $\mathrm{EP}$ & 5 & $-^{4}$ & - \\
\hline Erysimum, flower & Erysimum cheiri & EPP & 4 & 2 & 4 \\
\hline Cerinthe, flower & Cerinthe major & $\mathrm{CBP}$ & 5 & - & - \\
\hline Lupin, flower & Lupinus graecus & $\mathrm{HBP}$ & 5 & 2 & 4 \\
\hline \multicolumn{6}{|c|}{ Local market, Fermoy, Co. Cork, Ireland } \\
\hline Grapes, fruit & Vitis vinifera & GFM & 3 & - & - \\
\hline Banana, fruit & Musa acuminate & BFM & 5 & - & - \\
\hline Cauliflower, vegetable & Brassica oleracea & CVM & 5 & - & - \\
\hline Spinach, vegetable & Spinacia oleracea & SVM & 3 & - & - \\
\hline Total $(\mathrm{n}=19)$ & & & 141 & 45 & 100 \\
\hline
\end{tabular}




\section{Detection of the mdh Gene}

To identify strains with the genetic potential to produce mannitol, gradient PCR was standardized with an $m d h$-positive strain Limosilactobacillus reuteri DSM 20016, which generated an amplified product of 190 bp (Supplemental Figure S1, https://doi.org/10.3168/ jds.2020-19120). Of the 45 strains tested, 26 L. mesenteroides and 5 Fructobacillus strains were found to possess the $m d h$ gene (Figure 2). The $m d h$ gene was not detected in 4 L. mesenteroides strains (DPC 7242, DPC 7256, DPC 7271, DPC 7273), 2 L. mesenteroides ssp. jonggajibkimchii strains (DPC 7262 and DPC 7272), and $F$. fructosus strain DPC 7239. Other LAB species such as L. lactis (DPC 7230 and DPC 7236), Lactiplantibacillus plantarum (DPC 7247), and 4 non-LAB species were also $m d h$-negative according to PCR analysis.

\section{Fructose Tolerance by LAB Isolates}

In the presence of $10 \%$ and $20 \%$ fructose, all 31 $m d h$-positive strains grew well, exhibiting from 80.96 $\pm 1.79 \%$ to $100.91 \pm 0.12 \%$ fructose tolerance. The highest values were observed in L. mesenteroides DPC $7234(100.91 \%)$ at $10 \%$ fructose and in F. fructosus DPC 7235 (100.61\%) at 20\% fructose (data not shown). Figure 3 shows the results of fructose tolerance tests at higher concentrations of fructose (30,40, and 50\%) in FMRS. At each fructose concentration, different strains exhibited the highest fructose tolerance (e.g., DPC 7240 at 30\%, and DPC 7238 at 40 and 50\%), but strains such as L. mesenteroides DPC 7232 and DPC 7261, F. fructosus DPC 7237, and F. fructosus DPC 7238 consistently showed better tolerance. Lactococcus lactis DPC 6665, Limosilactobacillus reuteri

A.
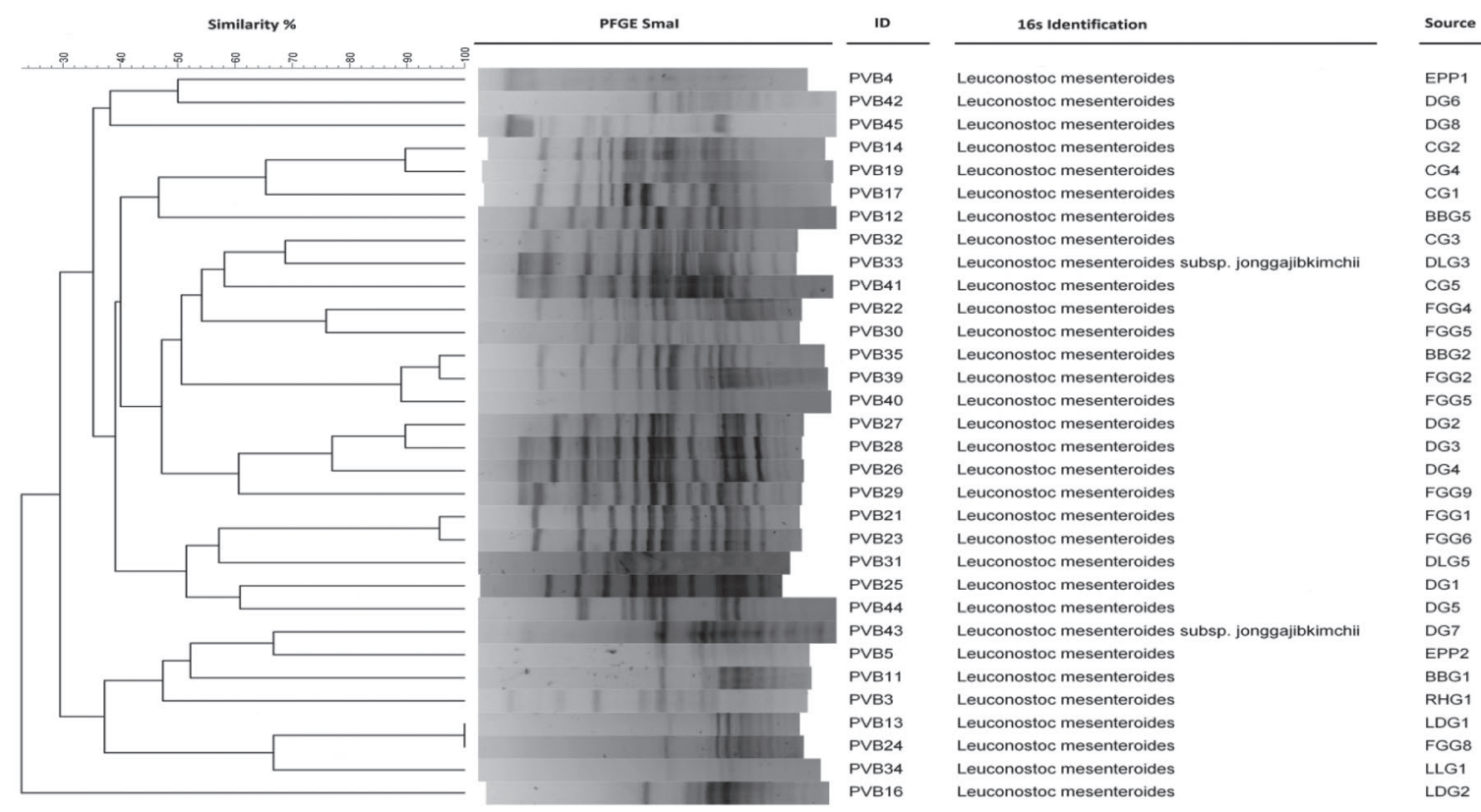

DPC code

Similarity $\%$

PFGE Sfil

ID

B.
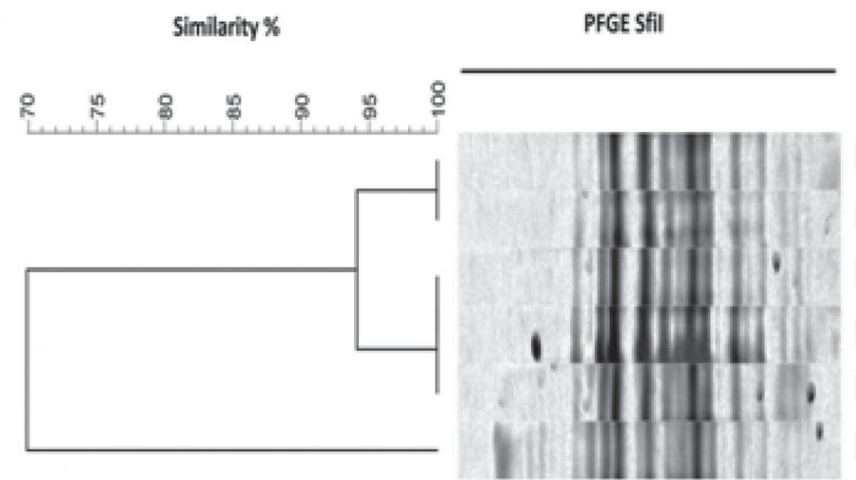

PVB38

Fructobacillus fructosus

WCG3

DPC 7267

PVB6

Fructobacillus fructosus

WCG4

DPC 7235

PVB10

Fructobacillus fructosus

HBP1

DPC 7239

PVB37

Fructobacillus fructosus

WCG2

DPC 7266

PVB9

Fructobacillus fructosus

WCG5

DPC 7238

PVB8

Fructobacillus fructosus

WCG1

DPC 7237

Figure 1. Dendrograms based on unweighted pair group method with arithmetic mean (UPGAMA) clustering (Dice coefficient) of pulsedfield gel electrophoresis (PFGE) profiles. (A) Leuconostoc mesenteroides strains; (B) Fructobacillus fructosus. DPC = Dairy Production Centre, from the Teagasc Moorepark Culture Collection; SmaI and SfiI = restriction enzymes. 


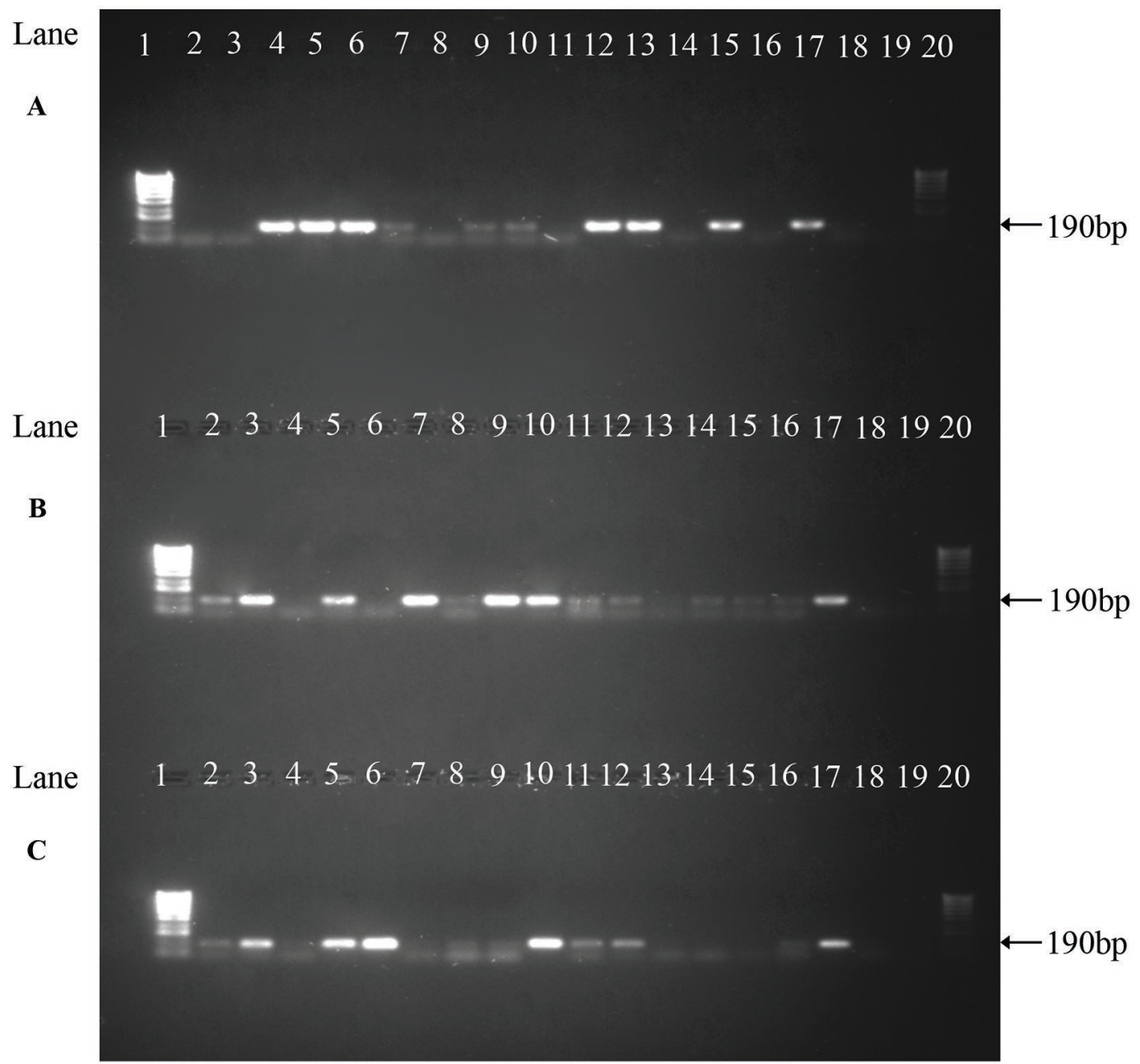

Figure 2. Detection of $m d h$ gene by PCR in fructophilic lactic acid bacteria (FLAB) isolates. (A) Lanes: $1=100-b p$ ladder, $2=$ DPC 7230 $3=\operatorname{DPC} 7231,4=\operatorname{DPC} 7232,5=\operatorname{DPC} 7233,6=\operatorname{DPC} 7234,7=\mathrm{DPC} 7235,8=\mathrm{DPC} 7236,9=\mathrm{DPC} 7237,10=\mathrm{DPC} 7238,11=\mathrm{DPC}$ $7239,12=$ DPC 7240, $13=$ DPC 7241, $14=$ DPC 7242, $15=$ DPC 7243, $16=$ DPC $7244,17=$ DSM $20016,18=$ water control, $19=$ buffer control, $20=100$-bp ladder. (B) Lanes: $1=100$-bp ladder, $2=$ DPC $7245,3=$ DPC $7246,4=\mathrm{DPC} 7247,5=\mathrm{DPC} 7248,6=\mathrm{DPC} 7249,7$ $=\operatorname{DPC} 7250,8=\operatorname{DPC} 7251,9=\mathrm{DPC} 7252,10=\mathrm{DPC} 7253,11=\mathrm{DPC} 7254,12=\mathrm{DPC} 7255,13=\mathrm{DPC} 7256,14=\mathrm{DPC} 7257,15=\mathrm{DPC}$ 7258, 16 = DPC 7259, 17 = DSM20016, $18=$ water control, $19=$ buffer control, $20=100$-bp ladder. (C) Lanes: $1=100$-bp ladder, $2=$ DPC $7260,3=$ DPC $7261,4=$ DPC $7262,5=$ DPC $7263,6=$ DPC $7264,7=$ DPC $7265,8=$ DPC $7266,9=\mathrm{DPC} 7267,10=\mathrm{DPC} 7268,11=$ DPC 7269, $12=$ DPC 7270, $13=$ DPC $7271,14=$ DPC $7272,15=$ DPC $7273,16=$ DPC $7274,17=$ DSM20016, $18=$ water control, $19=$ buffer control, 20 = 1-kb ladder. DSM = Deutsche Sammlung von Mikroorganismen und Zellkulturen GmbH; DPC = Dairy Production Centre, from the Teagasc Moorepark Culture Collection.

DSM 20016, and L. mesenteroides DPC 7274 did not grow at concentrations higher than $10 \%, 30 \%$, and $40 \%$ fructose, respectively.

\section{Screening of mdh-Positive FLAB for Mannitol Production}

Mannitol production ranged from $0.18 \pm 0.003$ to $16.24 \pm 0.08 \mathrm{~g} / \mathrm{L}$ and $2.19 \pm 0.04$ to $14.98 \pm 0.25 \mathrm{~g} / \mathrm{L}$ for Leuconostoc and Fructobacillus cultures, respectively (Figure 4$)$. We observed a difference $(P<0.001)$ between the positive control, Limosilactobacillus reuteri DSM 20016, and the 22 strains under investigation. Six strains (DPC 7232, DPC 7237, DPC 7238, DPC 7255, DPC 7260, and DPC 7261) produced higher amounts of mannitol $(>12.57 \pm 0.14 \mathrm{~g} / \mathrm{L})$ than DSM 20016 (10.79 $\pm 0.20 \mathrm{~g} / \mathrm{L}$ ), with the remainder showing similar or lower levels of mannitol. In general, L. mesenteroides DPC 7261 and F. fructosus DPC 7238 produced significantly higher mannitol concentrations $(P<0.0001)$ in Leuconostocs and Fructobacillus groups respectively. Leuconostoc mesenteroides DPC 7232 and F. fructosus 
DPC 7237 were the second highest mannitol producers. Two L. mesenteroides strains (DPC 7234 and DPC 7241) were unable to produce mannitol.

Based on the results of the fructose tolerance and mannitol production assays, 4 fructophilic strains, 2 L. mesenteroides (DPC 7232 and DPC 7261) and 2 Fructobacillus species (F. fructosus DPC 7237 and F. fructosus DPC 7238) were selected for further study.

\section{Mannitol Production, Yield, and Productivity in FMRS and FM}

Table 2 depicts the FLAB directed fermentation parameters, such as fructose consumption, mannitol production, productivity, and yield in FMRS and FM. All 4 strains displayed high fructose utilization $(>9$ $\mathrm{g} / \mathrm{L})$, consumption rate $(>0.45 \mathrm{~g} / \mathrm{g}$ per $\mathrm{h})$ and produced mannitol at high yields $(>0.89 \mathrm{~g}$ of mannitol $/ \mathrm{g}$ of fructose) with relatively greater volumetric productivities $(>0.021)$ in FMRS. These values were much higher than those observed for Limosilactobacillus reuteri DSM 20016. The best yields were obtained for F. fructosus DPC 7238, followed by L. mesenteroides
DPC 7261. Fructobacillus fructosus DPC 7238 utilized most of the fructose $(9.27 \mathrm{~g})$ present in the FMRS, with consumption rate of $0.46 \mathrm{~g} / \mathrm{g}$ per $\mathrm{h}$ and produced as much as $9.19 \mathrm{~g} / \mathrm{L}$ of mannitol with yield of $0.99 \mathrm{~g} / \mathrm{g}$ of fructose.

Although the yields of mannitol and other parameters were lower in FM than in FMRS, they were higher for all fructophilic strains isolated in this study compared with the positive control L. reuteri DSM 20016 (Table 2). Leuconostoc mesenteroides DPC 7261 demonstrated the highest values for all calculated fermentation parameters in FM, exhibiting higher fructose consumption, mannitol production, and yield than the other strains (Table 2). Fructobacillus fructosus DPC 7238 was slightly less efficient, utilizing $8.57 \mathrm{~g} / \mathrm{L}$ fructose and producing $4.25 \mathrm{~g} / \mathrm{L}$ of mannitol with yield of 0.50 $\mathrm{g} / \mathrm{g}$ of fructose in FM.

\section{Milk Gelation by FLAB}

The milk gelation ability demonstrated by FLAB strains is presented in Figure 5. The gelation point expressed in time (s) was considered when the stor-

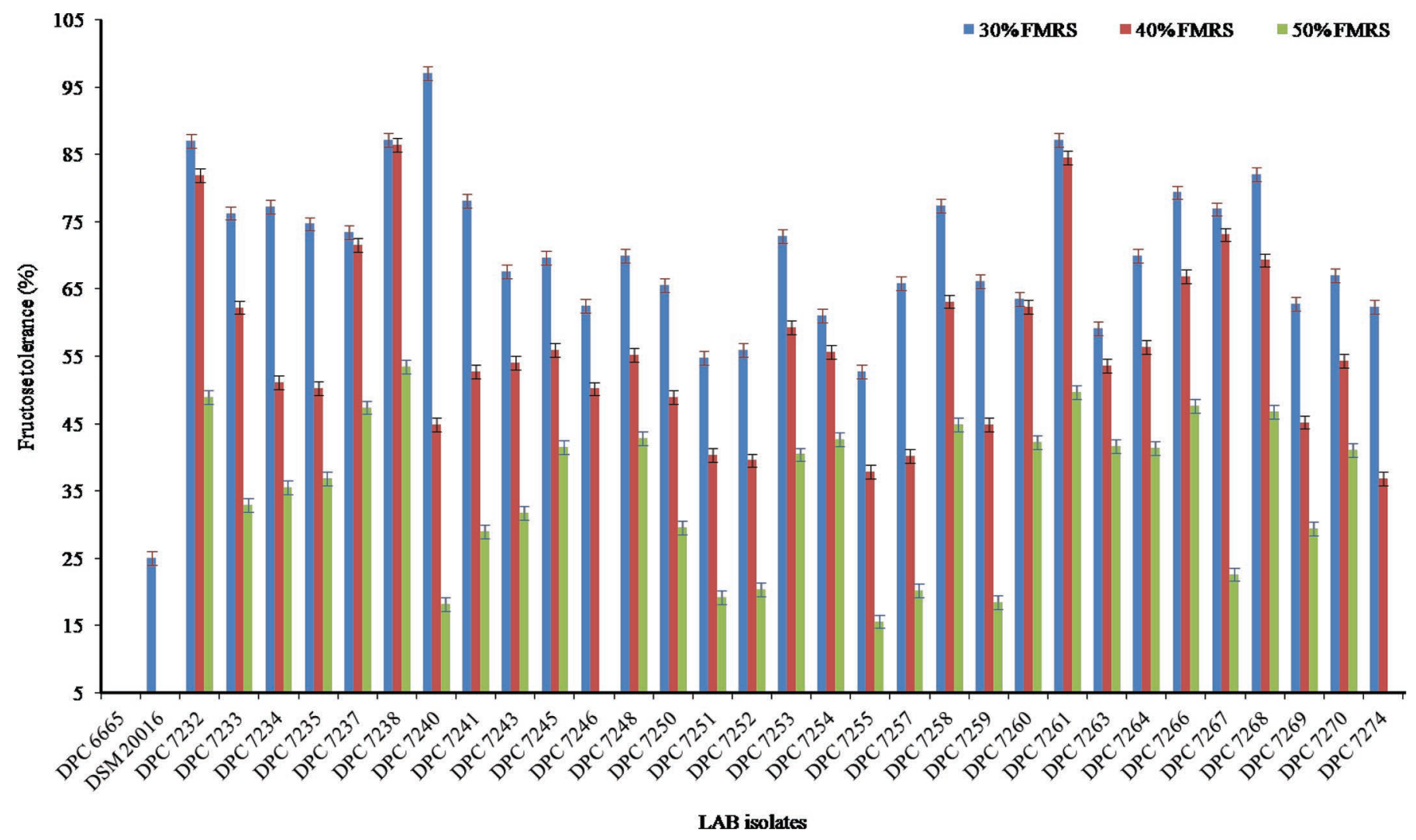

Figure 3. Fructose tolerance $(\%)$ by lactic acid bacteria (LAB) isolates (mean \pm SEM). FMRS = fructose de Man, Rogosa, and Sharpe broth. Fructose tolerance (\%) values for LAB isolates were between 80.96 and $100.36 \%$, whereas DSM 20016 tolerance values were between 80.74 and $96.70 \%$ at 20 and 10\%, respectively; DSM 20016 growth was not observed at 40\% FMRS. DSM = Deutsche Sammlung von Mikroorganismen und Zellkulturen GmbH; DPC = Dairy Production Centre, from the Teagasc Moorepark Culture Collection. 
Table 2. Fructose consumption and mannitol production, productivity, and yield in FMRS and FM ${ }^{1}$

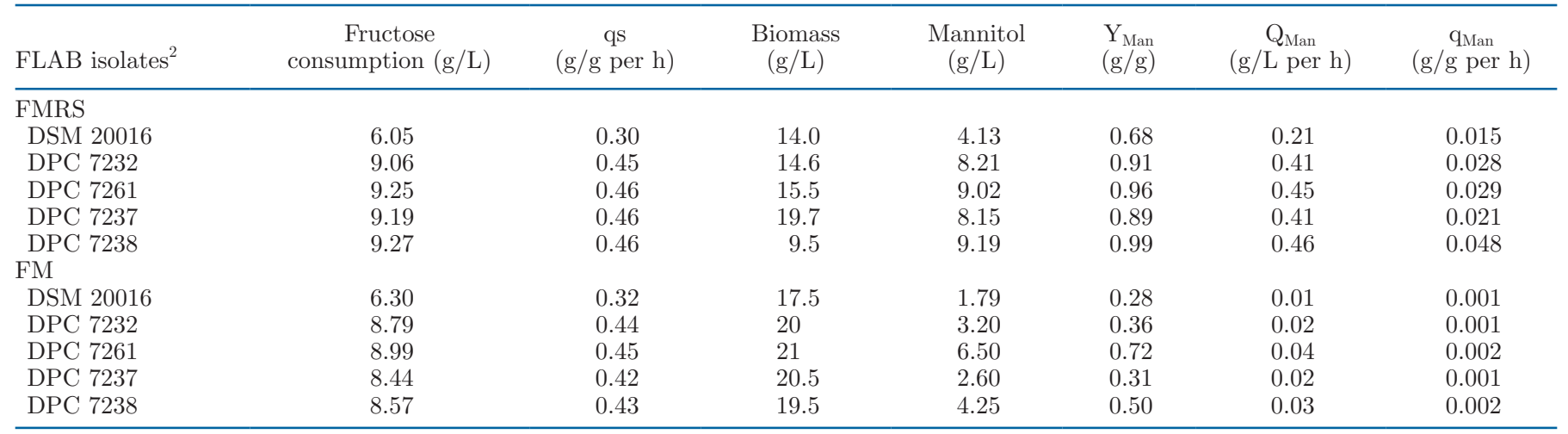

${ }^{1}$ FMRS $=1 \%$ fructose de Man, Rogosa, and Sharpe broth; FM = 1\% fructose milk; DSM = Deutsche Sammlung von Mikroorganismen und Zellkulturen $\mathrm{GmbH}$; DPC = Dairy Production Centre, from the Teagasc Moorepark Culture Collection. Fructose consumption $(\mathrm{g} / \mathrm{L})=$ fructose content in samples before fermentation - fructose content in samples after fermentation. Fructose consumption rate $(\mathrm{qs}$, g/L per $\mathrm{h})=$ fructose consumption/time. Yield of mannitol $\left(\mathrm{Y}_{\mathrm{Man}}\right)$ from fructose $(\mathrm{g} / \mathrm{g})$ - mannitol produced in sample/fructose consumed in sample. Volumetric mannitol production rate $\left(\mathrm{Q}_{\mathrm{Man}}, \mathrm{g} / \mathrm{L}\right.$ per $\left.\mathrm{h}\right)=$ mannitol produced in samples/time. Specific mannitol production rate $\left(\mathrm{q}_{\mathrm{Man}}, \mathrm{g} / \mathrm{g}\right.$ per $\left.\mathrm{h}\right)=\mathrm{Q}_{\mathrm{Man}} /$ wet biomass $(\mathrm{g} / \mathrm{L})$.

${ }^{2} \mathrm{FLAB}=$ fructophilic lactic acid bacteria.

age modulus $\left(\mathrm{G}^{\prime}\right)$ was above $0.1 \mathrm{~Pa}$. The onset of milk gelation $\left(\mathrm{G}^{\prime}>0.1 \mathrm{~Pa}\right)$ for Fructobacillus strains occurred between 41,667 and 42,238 s, whereas for $L$. mesenteroides strains, it was observed between 52,256 and $53,370 \mathrm{~s}$. In the case of milk inoculated with $L$. reuteri DSM 20016, gelation commenced at 31,428 s.

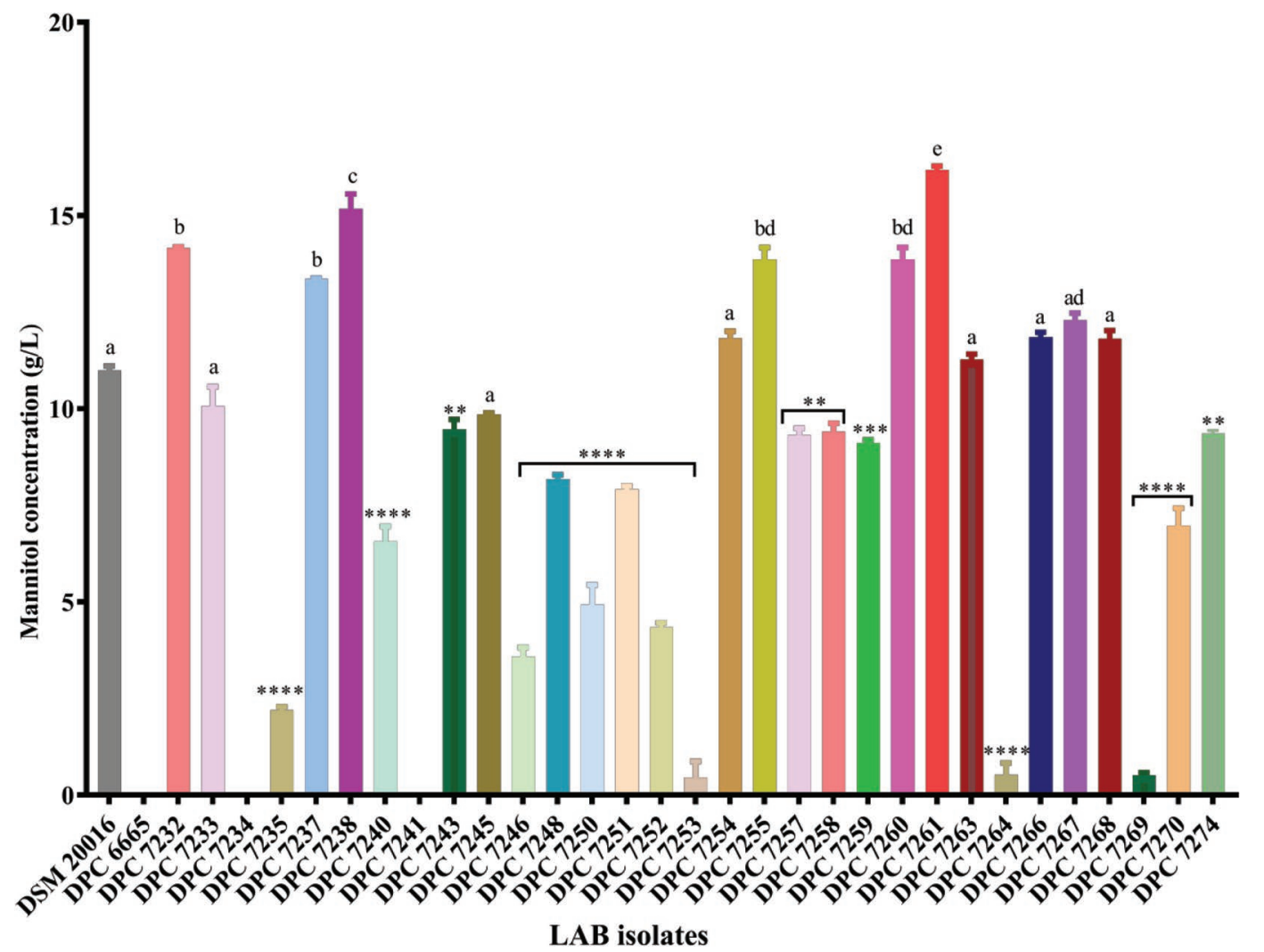

Figure 4. Mannitol production (mean \pm SEM) by fructophilic lactic acid bacteria (LAB) using enzyme kit. Differences were compared with DSM 20016. DSM = Deutsche Sammlung von Mikroorganismen und Zellkulturen GmbH; DPC = Dairy Production Centre, from the Teagasc Moorepark Culture Collection. a-e: Different lowercase letters differ $(P<0.01$ or $P<0.0001)$. ${ }^{* *} P<0.01 ;{ }^{* * *} P<0.001 ; * * * * P<0.0001$. 


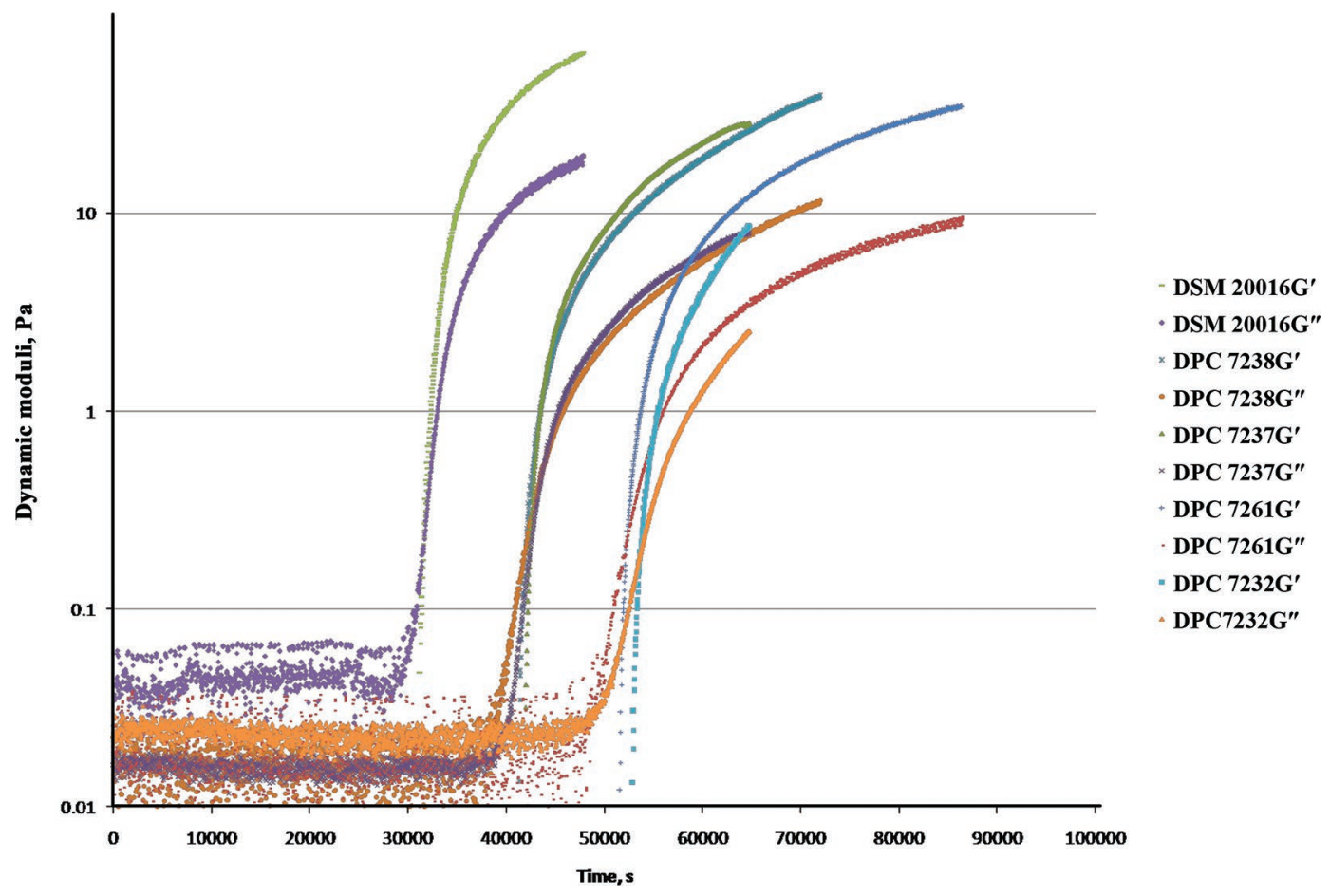

Figure 5. Changes of elastic modulus $\left(\mathrm{G}^{\prime}\right)$ and viscous modulus $\left(\mathrm{G}^{\prime \prime}\right)$ of $1 \%$ fructose milk with Limosilactobacillus reuteri DSM 20016 , Fructobacillus fructosus DPC 7238, Fructobacillus fructosus DPC 7237, Leuconostoc mesenteroides DPC 7261, and L. mesenteroides DPC 7232. Milk gelation point: $\mathrm{G}^{\prime}>0.1 \mathrm{~Pa}$.

Milk gelation times for various strains were in the order of DSM $20016>$ DPC7238 > DPC7237 > DPC7261 $>$ DPC7232. The viscous modulus $\left(\mathrm{G}^{\prime \prime}\right)$ values for the FLAB strains isolated in this study followed a trend quite similar to that of $\mathrm{G}^{\prime}$. However, the $\mathrm{G}^{\prime \prime}$ values were observed to be smaller than the $G^{\prime}$ values for all the strains. $A G^{\prime}$ value that is higher than the $G^{\prime \prime}$ indicates the elastic character of a gel.

\section{DISCUSSION}

Although FLAB species have recently received renewed interest due to their possible use as mannitol producers, such strains have not yet been well characterized from a technological standpoint in dairy applications. The ability of LAB and FLAB species to produce high mannitol concentrations may provide an opportunity for the development of in situ mannitol-enriched fermented food products (Ruiz Rodríguez et al., 2017). In addition, mannitol production by these cultures as food or pharmaceutical compounds without sorbitol may be a promising alternative to chemical processes (Ruiz Rodríguez et al., 2017). Here, we generated a bank of mannitol-producing isolates from fructose-rich sources and investigated their potential for application in dairy. Our sources consisted of flowers, honey, fruits, and vegetables. Previously, FLAB have been isolated from fruits and vegetables (Edwards et al., 1998; Trias et al., 2008; Emerenini et al., 2013; Wu et al., 2014); however, we were unable to retrieve these organisms from the fruit and vegetable samples tested in this study. Environmental conditions and geographical locations that shape microbial communities, handling, storage conditions, and other factors may affect the occurrence of LAB in fruits and vegetables (Alvarez-Pérez et al., 2012; Samuni-Blank et al., 2014). By contrast, the flower and honey samples proved to be a rich source of LAB and FLAB. Leuconostoc mesenteroides was widely distributed among all the flower types. Interestingly, 2 strains of the subspecies L. mesenteroides ssp. jonggajibkimchii were found, one associated with dandelion flower and one associated with its leaves. Our PFGE analysis showed these as quite distinct strains genetically. The remaining $L$. mesenteroides strains from the various flower sources were also quite distinct by PFGE, with several different pulsotypes identified. Fructobacillus species such as F. fructosus were present mainly in white clover, with the exception of $F$. fructosus DPC 7239 , which was present in lupin. Previously, few Fructobacillus species have been reported in flowers (Endo et al., 2009; Endo, 2012). The occurrence and dominance of specific species in plants and flowers is generally 
dependent on the season, the flower, and also the pollinators visiting the flower. We found that samples of leaves, flowers housing honeybees, and raw honey gathered from the Tipperary farm provided large numbers of LAB isolates with fructophilic behavior compared with the wild flower samples gathered from the garden in Kilworth. This may well be explained by the fact that the Tipperary farm rears Native Irish Black Queen bees (Apis mellifera mellifera) for honey production, which potentially transfer fructophilic microflora onto the flowers. This is supported by other studies, which report that honeybees and insects are vital sources of FLAB (Holzapfel and Wood, 2014; Endo et al., 2018). Species of FLAB, especially Apilactobacillus kunkeei and F. fructosus, found as microbial components in the digestive tract of honeybees (Endo and Salminen, 2013; Filannino et al., 2016), were also present in flower inhabitants (Endo et al., 2009), suggesting that bees share their gut microorganisms with their diet sources. In contrast to the results obtained for L. mesenteroides and its subspecies, PFGE analysis of the Fructobacillus isolates revealed similarities between all the strains, irrespective of the source. Fructobacillus fructosus DPC 7239, obtained from Lupinus graecus flowers in Kilworth, and $F$. fructosus DPC 7266, obtained from Trifolium repens flowers collected from the Tipperary farm, showed $100 \%$ similarity when analyzed by Bionumerics. In the case of $F$. fructosus, DPC 7237 was $70 \%$ similar to other isolates from the same flower (white clover). Also, F. fructosus DPC 7238, obtained from Trifolium repens flowers collected in Kilworth, despite being a separate species, showed $100 \%$ similarity with other F. fructosus isolates. Fructobacillus fructosus and $F$ durionis are very closely related species, and it may be the case that the discriminatory power of PFGE is insufficient to separate them.

Bacterial species harboring the $m d h$ gene are often capable of producing mannitol from fructose, and this characteristic has been reported in L. mesenteroides, $L$. pseudomesenteroides, Lactobacillus, and Fructobacillus species (Aarnikunnas et al., 2002; Korakli and Vogel, 2003; Ruiz Rodríguez et al., 2017). Of the 41 strains of Leuconostoc and Fructobacillus strains tested, 31 were shown to harbor this gene, which may be attributed to their origin, a high fructose-rich environment. Previously, mdh-associated mannitol production has been reported in most FLAB isolated from fructose-rich flowers, fruits, and insect intestines (Endo et al., 2009; Filannino et al., 2016). As evidenced from the fructose tolerance assay, all $m d h$-positive LAB strains demonstrated high fructose-tolerating capabilities, with some growing well at 10 and $20 \%$ fructose in MRS broth. Fructose tolerance declined as the fructose concentration increased above $20 \%$, but the decrease was strain- dependent. Fructobacillus fructosus DPC 7238, F. fructosus DPC 7237, L. mesenteroides DPC 7261, and L. mesenteroides DPC 7232 displayed relatively better tolerance in all fructose concentrations tested but particularly at the higher concentrations (50\%). These strains were isolated from leaves, honey, and fructoserich flowers that house honeybees, and therefore it was not unexpected that they tolerated fructose concentrations as high as $50 \%$ in the growth media. In agreement with our results, fructophilic Lactiplantibacillus plantarum FPL strain isolated from honeydew could tolerate 20 to $50 \%$ glucose or fructose in the MRS and FYP broth, as evidenced by visible growth as biomass and turbidity at the bottom of the tube after 24 to $48 \mathrm{~h}$ of incubation (Gustaw et al., 2018). As mentioned earlier, Fructobacillus and L. mesenteroides strains isolated in this study required fructose for their growth and showed delayed or no growth in the absence of fructose. This property is known for FLAB, especially Fructobacillus spp. and some Lactobacillus spp. (such as Apilactobacillus kunkeei, Apilactobacillus apinorum, and Fructilactobacillus florum), but is rarely seen in L. mesenteroides (Endo et al., 2018; Filannino et al., 2018, 2019; Maeno et al., 2019). It has been found that FLAB species prefer fructose over glucose, utilizing fewer carbohydrates, and have specific genome reductions uncommon to LAB (Endo et al., 2018). Recently, fructophilic-like growth characteristics (called pseudofructophilic activity) has been reported in Leuconostoc species, specifically Leuconostoc citreum $\mathrm{F}-192-5$, isolated from the peel of the satsuma mandarin (Maeno et al., 2019). Unlike FLAB, strain F-192-5 possesses phenotypically and genetically rich carbohydrate metabolic systems, with a genome size comparable to those of nonfructophilic L. citreum strains. Although pseudofructophilic activity was strain-specific, it is not surprising that such a property can be observed in many other LAB species present in fructose-rich niches, as was the case in our isolated strains, henceforth called FLAB. However, a detailed investigation of specific carbohydrate utilization patterns and genomic arrangements in this strain of $L$. citreum and the Leuconostoc strains isolated in this study would be required to further understand their fructophilic behavior and niche adaptability.

Mannitol production varied among the strains tested, with 16 Leuconostoc and 5 Fructobacillus strains producing more than $5 \mathrm{~g} / \mathrm{L}$ of mannitol from $10 \mathrm{~g} / \mathrm{L}$ of fructose. Similarly, Filannino et al. (2018) reported that 6 out of 24 mannitol-producing strains of the genera Leuconostoc and Fructobacillus synthesized mannitol in concentrations higher than $5 \mathrm{~g} / \mathrm{L}$ from 10 $\mathrm{g} / \mathrm{L}$ of fructose. Eighteen strains produced mannitol at concentrations higher than or similar to that of the control strain Limosilactobacillus reuteri DSM 20016, 
originally isolated from human feces (Sriramulu et al., 2008; Carvalheiro et al., 2011). In previous studies, 8 of 13 FLAB strains, mainly fructobacilli isolated from fructose-rich fruits, produced 7.76 to $9.46 \mathrm{~g} / \mathrm{L}$ of mannitol from $10 \mathrm{~g} / \mathrm{L}$ of fructose (Ruiz Rodríguez et al., 2017). Fructophilic LAB strains isolated from bee intestines, including 5 strains of $F$. fructosus, produced significant quantities of mannitol in the fructose-rich medium (Filannino et al., 2016). We observed $2 \mathrm{mdh}$ positive strains, L. mesenteroides DPC 7234 and DPC 7241 , that were unable to produce mannitol, which may be a consequence of gene mutation and merits further investigation. Notably, L. mesenteroides DPC 7261, F. fructosus DPC 7238, F. fructosus DPC 7237, and $L$. mesenteroides DPC 7232, which demonstrated higher fructose tolerance, were also the superior mannitolproducing strains, and were thus investigated further for mannitol production in batch method and milk fermentation.

Fermentation parameters, such as fructose consumption, mannitol production, yield, and volumetric productivities, calculated by chromatography methods, are reported in several LAB strains (Korakli et al., 2000; Wisselink et al., 2002; Ortiz et al., 2012). These parameters have been found to be rationale for the selection of superior mannitol-producing cultures for industrial applications (von Weymarn et al., 2002; Saha, 2006a). All the selected FLAB strains showed either similar or higher mannitol yields (0.89 to 0.99 $\mathrm{g} / \mathrm{g}$ of fructose) compared with most of the LAB strains (0.70 to $0.96 \mathrm{~g} / \mathrm{g}$ of fructose) studied by Carvalheiro et al. (2011), except Lactobacillus fructosum. Earlier, Saha (2006b) showed $200 \mathrm{~g} / \mathrm{L}$ of mannitol production $(0.67 \mathrm{~g} / \mathrm{g}$ of fructose, yield) from L. intermedius NRRL B3693, using a simplified medium comprising $300 \mathrm{~g} / \mathrm{L}$ fructose in the batch method. Upon comparison of the mannitol concentrations obtained by HPLC and the enzymatic method, we found some discrepancies, with the latter overestimating the mannitol level $(>10 \mathrm{~g} / \mathrm{L}$ from $10 \mathrm{~g} / \mathrm{L}$ of fructose). However, the enzyme-based method is suitable as an initial screening tool. Previously, FLAB strains have been reported to utilize more fructose and produce higher mannitol concentrations because of their peculiar fructophilic metabolism (Ruiz Rodríguez et al., 2017; Filannino et al., 2018). Here, F. fructosus DPC 7238 and L. mesenteroides DPC 7261 consumed fructose at the highest rates and were also the best mannitol producers in FMRS. These strains also showed the highest volumetric productivities $(0.46$ and $0.45 \mathrm{~g} / \mathrm{L}$ per $\mathrm{h}$, respectively, by DPC 7238 and DPC 7261). A similar trend was observed for fructose consumption and mannitol production parameters in FM, but L. mesenteroides DPC 7261 performed better in FM, indicating that each strain differs in its mannitol-producing ability with respect to growth medium. Fructobacillus fructosus DPC 7238, producing $4.25 \mathrm{~g} / \mathrm{L}$ of mannitol in FM with a yield of $0.50 \mathrm{~g} / \mathrm{g}$ of fructose, seems satisfactory for a nondairy-origin FLAB strain.

The onset of $1 \% \mathrm{FM}$ gelation time varied with the FLAB strains, and was found to be shorter for DSM 20016 and Fructobacillus than for the Leuconostoc strains. These strains were also found to lower the $\mathrm{pH}$ of FM in a similar fashion, with the largest drop in $\mathrm{pH}$ observed for DSM 20016 (up to $\mathrm{pH}$ 4.72) followed by DPC 7238 (up to $\mathrm{pH} 4.9$ ) after $20 \mathrm{~h}$ of incubation (Supplemental Figure S2, https://doi.org/10.3168/jds.2020 -19120). However, the time required for complete gelation by these strains was quite long, and the gel formed, as observed visually, was not as firm as that produced by typical dairy strains (Gentès et al., 2011). Fructophilic LAB species are heterofermentative, producing lactate, acetate, and $\mathrm{CO}_{2}$ (Chuah et al., 2016; Endo et al., 2018; Maeno et al., 2019), thus lowering the $\mathrm{pH}$ of the milk. It is also important to note that these cultures were subcultured repeatedly in fructose-containing milk, for their increased adaptability to the dairy environment. Weaker gel strength is associated with protein-protein interactions, and longer fermentation time with inherent capacities and proteolytic activity of the strains, which as of now, are poorly understood in these strains. Comparing mannitol production and milk gelation, $L$. mesenteroides DPC 7261 produced the highest mannitol concentration in the milk but required longer time than F. fructosus DPC 7238 to reach the gelling point in FM. Nevertheless, it is fascinating that the isolates obtained from fructose-rich niches may also be adapted to the milk system.

Although the milk gelation point varies from strain to strain (from 4 to $12 \mathrm{~h}$, depending on the strain), the strains isolated in our study took longer than recognized dairy strains to reach the same gelation point. As functional starters in the production of fermented dairy products, these strains could have commercial potential for naturally produced mannitol in products such as stirred yogurt, cultured buttermilk, and dairy or nondairy beverages. For more set types of fermented dairy products, the weaker gel strength exhibited by these strains may require coculture with strains with enhanced capability in this regard. Further studies are required to focus on the technological and rheological properties of these strains in conjunction with other application-specific starters. Compatibility studies with dairy starters will provide an opportunity for novel dairy starter formulation, for development of innovative dairy products naturally sweetened with this lowcalorie sugar. 


\section{CONCLUSIONS}

Flowers housing honeybees were found to be a potential reservoir for fructophilic LAB species. Leuconostoc mesenteroides strains were widely distributed among the flowers, whereas fructobacilli were mainly isolated from white clover. The majority of the $L$. mesenteroides and Fructobacillus strains had the genetic and phenotypic capability to produce mannitol. With respect to fructose consumption, mannitol yield and volumetric mannitol productivities, F. fructosus DPC 7238 in FMRS and L. mesenteroides DPC 7261 in fermented milk showed the best results. These strains also took a relatively short time for gelation of milk. This finding suggests that L. mesenteroides DPC 7261 and F. fructosus DPC 7238, producing significant amounts of mannitol in milk and exhibiting milk gelation behavior, could be considered in starter or adjunct culture formulations for the development of in situ mannitol-enriched fermented dairy products.

\section{ACKNOWLEDGMENTS}

The authors thank Helen Slattery, Prateek Sharma, and Seán Hogan of Teagasc for their technical assistance. This work was funded by Teagasc and Dairy Research Ireland (Teagasc Food Research Centre, Moorepark, Ireland). P. V. Behare is thankful to Institutional Development Plan-National Agricultural Higher Education Project (IDP-NAHEP), ICAR-National Dairy Research Institute, Karnal, Haryana, India, for providing a faculty development grant for research training at Teagasc Food Research Centre, Moorepark, Fermoy, Cork, Ireland. The authors declare that this research was conducted in the absence of any commercial or financial relationships that could be construed as a potential conflict of interest.

\section{REFERENCES}

Aarnikunnas, J., K. Ronnholm, and A. Palva. 2002. The mannitol dehydrogenase gene $(m d h)$ from Leuconostoc mesenteroides is distinct from other known bacterial $m d h$ genes. Appl. Microbiol. Biotechnol. 59:665-671. https://doi.org/10.1007/s00253-002-1070-0.

Alander, M., R. Satokari, R. Korpela, M. Saxelin, T. VilpponenSalmela, T. Mattila-Sandholm, and A. von Wright. 1999. Persistence of colonization of human colonic mucosa by a probiotic strain, Lactobacillus rhamnosus GG, after oral consumption. Appl. Environ. Microbiol. 65:351-354. https://doi.org/10.1128/AEM.65 1.351-354.1999.

Alvarez-Pérez, S., C. M. Herrera, and C. de Vega. 2012. Zooming in on floral nectar: A first exploration of nectar-associated bacteria in wild plant communities. FEMS Microbiol. Ecol. 80:591-602. https: //doi.org/10.1111/j.1574-6941.2012.01329.x.

Askari, G., A. Kahouadji, K. Khedid, R. Charof, and Z. Mennane. 2012. Screening of lactic acid bacteria isolated from dried fruits and study of their antibacterial activity. Middle East J. Sci. Res. 11:209-215.
Bhatt, S. M., A. Mohan, and S. K. Srivastava. 2012. Challenges in enzymatic route of mannitol production. ISRN Biotechnol. 2013:914187. https://doi.org/10.5402/2013/914187.

Carvalheiro, F., P. Moniz, L. C. Duarte, M. P. Esteves, and F. M. Gírio. 2011. Mannitol production by lactic acid bacteria grown in supplemented carob syrup. J. Ind. Microbiol. Biotechnol. 38:221227. https://doi.org/10.1007/s10295-010-0823-5.

Chuah, L. O., A. K. Shamila-Syuhada, M. T. Liong, A. Rosma, K. L. Thong, and G. Rusul. 2016. Physico-chemical, microbiological properties of tempoyak and molecular characterization of lactic acid bacteria isolated from tempoyak. Food Microbiol. 58:95-104. https://doi.org/10.1016/j.fm.2016.04.002.

Dhakal, R., V. K. Bajpai, and K.-H. Baek. 2012. Production of GABA ( $\gamma$-aminobutyric acid) by microorganisms: A review. Braz. J. Microbiol. 43:1230-1241. https://doi.org/10.1590/S1517 $-83822012000400001$.

Di Cagno, R., R. Coda, M. De Angelis, and M. Gobbetti. 2013. Exploitation of vegetables and fruits through lactic acid fermentation. Food Microbiol. 33:1-10. https://doi.org/10.1016/j.fm.2012 .09 .003 .

Edwards, C. G., K. M. Haag, M. D. Collins, R. A. Hutson, and Y. C. Huang. 1998. Lactobacillus kunkeei sp. nov.: a spoilage organism associated with grape juice fermentations. J. Appl. Microbiol. 84:698-702. https://doi.org/10.1046/j.1365-2672.1998.00399.x.

Emerenini, E., O. Afolabi, P. Okolie, and A. Akintokun. 2013. Isolation and molecular characterization of lactic acid bacteria isolated from fresh fruits and vegetables using nested PCR analysis. Br. Microbiol. Res. J. 3:368-377. https://doi.org/10.9734/BMRJ/ $2013 / 2520$.

Endo, A. 2012. Fructophilic lactic acid bacteria inhabit fructose-rich niches in nature. Microb. Ecol. Health Dis. 23:18563. https://doi .org/10.3402/mehd.v23i0.18563.

Endo, A., Y. Futagawa-Endo, and L. M. Dicks. 2009. Isolation and characterization of fructophilic lactic acid bacteria from fructoserich niches. Syst. Appl. Microbiol. 32:593-600. https://doi.org/10 .1016/j.syapm.2009.08.002.

Endo, A., Y. Futagawa-Endo, M. Sakamoto, M. Kitahara, and L. M. Dicks. 2010. Lactobacillus florum sp. nov., a fructophilic species isolated from flowers. Int. J. Syst. Evol. Microbiol. 60:2478-2482. https://doi.org/10.1099/ijs.0.019067-0.

Endo, A., S. Maeno, Y. Tanizawa, W. Kneifel, M. Arita, L. Dicks, and S. Salminen. 2018. Fructophilic lactic acid bacteria, a unique group of fructose fermenting microbes. Appl. Environ. Microbiol. 84:e01290-18. https://doi.org/10.1128/AEM.01290-18.

Endo, A., and S. Okada. 2008. Reclassification of the genus Leuconostoc and proposals of Fructobacillus fructosus gen. nov., Fructobacillus durionis comb. nov., Fructobacillus ficulneus comb.nov. and Fructobacillus pseudoficulneus comb. nov. Int. J. Sys. Evol. Microbiol. 58:2195-2205. https://doi.org/10.1099/ijs.0.65609-0.

Endo, A., and S. Salminen. 2013. Honeybees and beehives are rich sources for fructophilic lactic acid bacteria. Syst. Appl. Microbiol. 36:444-448. https://doi.org/10.1016/j.syapm.2013.06.002.

Famelart, M.-H., J. Tomazewski, M. Piot, and S. Pezennec. 2004. Comprehensive study of acid gelation of heated milk with model protein systems. Int. Dairy J. 14:313-321. https://doi.org/10 .1016/j.idairyj.2003.10.009.

Filannino, P., R. Di Cagno, R. Addante, E. Pontonio, and M. Gobbetti. 2016. Metabolism of fructophilic lactic acid bacteria isolated from the Apismellfera L., bee gut: Phenolic acids as external electron acceptors. Appl. Environ. Microbiol. 82:6899-6911. https:// doi.org/10.1128/AEM.02194-16.

Filannino, P., R. Di Cagno, and M. Gobbetti. 2018. Metabolic and functional path of lactic acid bacteria in plant foods: Get out of the labyrinth. Curr. Opin. Biotechnol. 49:64-72. https://doi.org/ 10.1016/j.copbio.2017.07.016.

Filannino, P., R. Di Cagno, A. Z. A. Tlais, V. Cantatore, and M. Gobbetti. 2019. Fructose-rich niches traced the evolution of lactic acid bacteria toward fructophilic species. Crit. Rev. Microbiol. 45:65-81. https://doi.org/10.1080/1040841X.2018.1543649.

Gentès, M.-C., D. St-Gelais, and S. L. Turgeon. 2011. Gel formation and rheological properties of fermented milk with in situ exopoly- 
saccharide production by lactic acid bacteria. Dairy Sci. Technol. 91:645-661. https://doi.org/10.1007/s13594-011-0039-0.

Gustaw, K., M. Michalak, M. Polak-Berecka, and A. Wasko. 2018. Isolation and characterization of a new fructophilic Lactobacillus plantarum FPL strain from honeydew. Ann. Microbiol. 68:459470. https://doi.org/10.1007/s13213-018-1350-2.

Holzapfel, W. H., and B. J. B. Wood. 2014. Lactic Acid Bacteria: Biodiversity and Taxonomy. John Wiley and Sons Ltd., West Sussex, UK. https://doi.org/10.1002/9781118655252.

Hunter, S. B., P. Vauterin, M. A. Lambert-Fair, M. S. Van Duyne, K. Kubota, L. Graves, D. Wrigley, T. Barrett, and E. Ribot. 2005. Establishment of a universal size standard strain for use with the PulseNet standardized pulsed-field gel electrophoresis protocols: converting the national databases to the new size standard. J. Clin. Microbiol. 43:1045-1050. https://doi.org/10.1128/JCM.43.3 $.1045-1050.2005$.

Korakli, M., E. Schwartz, G. Wolf, and W. P. Hammes. 2000. Production of mannitol by Lactobacillus sanfranciscensis. Adv. Food Sci. $22: 1-4$.

Korakli, M., and R. F. Vogel. 2003. Purification and characterization of mannitol dehydrogenase from Lactobacillus sanfranciscensis. FEMS Microbiol. Lett. 220:281-286. https://doi.org/10.1016/ S0378-1097(03)00129-0.

Leong, K.-H., Y.-S. Chen, S.-F. Pan, J.-J. Chen, H.-C. Wu, Y.-C. Chang, and F. Yanagida. 2014. Diversity of lactic acid bacteria associated with fresh coffee cherries in Taiwan. Curr. Microbiol. 68:440-447. https://doi.org/10.1007/s00284-013-0495-2.

Maeno, S., Y. Tanizawa, A. Kajikawa, Y. Kanesaki, E. Kubota, M. Arita, L. Dicks, and A. Endo. 2019. Pseudofructophilic Leuconostoc citreum strain F192-5 isolated from Satsuma Mandarin peel. Appl. Environ. Microbiol. 85:e01077-19. https://doi.org/10.1128/ AEM.01077-19.

McFrederick, Q. S., W. T. Wcislo, D. R. Taylor, H. D. Ishak, S. E. Dowd, and U. G. Mueller. 2012. Environment or kin: Where do bees obtain acidophilic bacteria? Mol. Ecol. 21:1754-1768. https:/ /doi.org/10.1111/j.1365-294X.2012.05496.x.

Mozzi, F., F. Vaningelgem, E. M. Hébert, R. V. Meulen, M. R. F. Moreno, G. F. de Valdez, and L. De Vuyst. 2006. Diversity of heteropolysaccharides producing lactic acid bacteria strains and their biopolymers. Appl. Environ. Microbiol. 72:4431-4435. https://doi .org/10.1128/AEM.02780-05.

Olofsson, T. C., E. Butler, P. Markowicz, C. Lindholm, L. Larsson, and A. Vasquez. 2014. Lactic acid bacterial symbionts in honebees-An unknown key to honey's antimicrobial and therapeutic activities. Int. Wound J. 13:668-679.

Ong, Y. Y., W. S. Tan, M. Rosfarizan, E. S. Chan, and B. Ti Tey. 2012. Isolation and identification of lactic acid bacteria from fermented red dragon fruit juices. J. Food Sci. 77:M560-M564. https: //doi.org/10.1111/j.1750-3841.2012.02894.x.

Ortiz, M. E., J. Bleckwedel, S. Fadda, G. Picariello, E. M. Hebert, R. R. Raya, and F. Mozzi. 2017. Global analysis of mannitol 2-dehydrogenase in Lactobacillus reuteri CRL 1101 during mannitol production through enzymatic, genetic and proteomic approaches. PLoS One 12:e0169441. https://doi.org/10.1371/journal.pone .0169441

Ortiz, M. E., M. J. Fornaguera, R. R. Raya, and F. Mozzi. 2012. Lactobacillus reuteri CRL 1101 highly produces mannitol from sugarcane molasses as carbon source. Appl. Microbiol. Biotechnol. 95:991-999. https://doi.org/10.1007/s00253-012-3945-z.

Pogačić, T., V. Chuat, M.-N. Madec, D. Samarzija, S. Lortal, and F. Valence. 2014. Phenotypic traits of genetically closely related
Leuconostoc spp. Int. Dairy J. 39:96-101. https://doi.org/10.1016/ j.idairyj.2014.05.014.

Ruiz Rodríguez, L. G. R., K. Aller, E. Bru, L. De Vuyst, E. M. Hebert, and F. Mozzi. 2017. Enhanced mannitol biosynthesis by the fruit origin strain Fructobacillus troaeoli CRL 2034. Appl. Microbiol. Biotechnol. 101:6165-6177. https://doi.org/10.1007/s00253-017 -8395-1.

Ruiz Rodríguez, L. G. R., F. Mohamed, J. Bleckwedel, R. Medina, L. De Vuyst, E. M. Hebert, and F. Mozzi. 2019. Diversity and functional properties of lactic acid bacteria isolated from wild fruits and flowers present in Northern Argentina. Front. Microbiol. 10:1091. https://doi.org/10.3389/fmicb.2019.01091.

Saha, B. C. 2006a. Production of mannitol from inulin by simultaneous enzymatic saccharification and fermentation with Lactobacillus intermedius NRRL B-3693. Enzyme Microb. Technol. 39:991-995. https://doi.org/10.1016/j.enzmictec.2006.02.001.

Saha, B. C. 2006b. A low-cost medium for mannitol production by Lactobacillus intermedius NRRL B-3693. Appl. Microbiol. Biotechnol. 72:676-680. https://doi.org/10.1007/s00253-006-0364-z.

Samuni-Blank, M., I. Izhaki, S. Laviad, A. Bar-Massada, Y. Gerchman, and M. Halpern. 2014. The role of abiotic environmental conditions and herbivory in shaping bacterial community composition in floral nectar. PLoS One 9:e99107. https://doi.org/10.1371/ journal.pone.0099107.

Sriramulu, D. D., M. Liang, D. Hernandez-Romero, E. Raux-Deery, H. Lunsdorf, J. B. Parsons, M. J. Warren, and M. B. Prentice. 2008. Lactobacillus reuteri DSM 20016 produces cobalamin-dependant dioldehydratase in metabolosomes and metabolizes 1,2-propanediol by disproportionation. J. Bacteriol. 190:4559-4567. https:// doi.org/10.1128/JB.01535-07.

Trias, R., L. Baneras, E. Montesino, and E. Badosa. 2008. Lactic acid bacteria from fresh fruit and vegetables as biocontrol agents of phytopathogenic bacteria and fungi. Int. Microbiol. 11:231-236. https://doi.org/10.2436/20.1501.01.66.

Tyler, C. A., I. Kopit, C. Doyle, A. O. Yu, J. Hugenholtz, and M. L. Marco. 2016. Polyol production during heterofermentative growth of the plant isolate Lactobacillus florum 2F. J. Appl. Microbiol. 120:1336-1345. https://doi.org/10.1111/jam.13108.

Vásquez, A., E. Forsgren, I. Fries, R. J. Paxton, E. Flaberg, L. Szekely, and T. C. Olofsson. 2012. Symbionts as major modulators of insect health: Lactic acid bacteria and honeybees. PLoS One 7:e33188. https://doi.org/10.1371/journal.pone.0033188.

von Weymarn, N., K. Kiviharju, and M. Leisola. 2002. High-level production of D-mannitol with membrane cell-recycle bioreactor. J. Ind. Microbiol. Biotechnol. 29:44-49. https://doi.org/10.1038/sj .jim.7000262.

Wisselink, H. W., R. A. Weusthuis, G. Eggink, J. Hugenholtz, and J. Grobben. 2002. Mannitol production by lactic acid bacteria: A review. Int. Dairy J. 12:151-161.

Wu, J., R. Du, M. Gao, Y. Sui, and X. Wang. 2014. Identification and characterization of lactic acid bacteria isolated from tomato pomace. Ann. Microbiol. 64:1849-1855. https://doi.org/10.1007/ s13213-013-0798-3.

\section{ORCIDS}

Pradip V. Behare @ https://orcid.org/0000-0002-0403-2398 Shahneela Mazhar ๑ https://orcid.org/0000-0002-5654-1338 Vincenzo Pennone @ https://orcid.org/0000-0001-8752-3231 Olivia McAuliffe @ https://orcid.org/0000-0003-2508-205X 